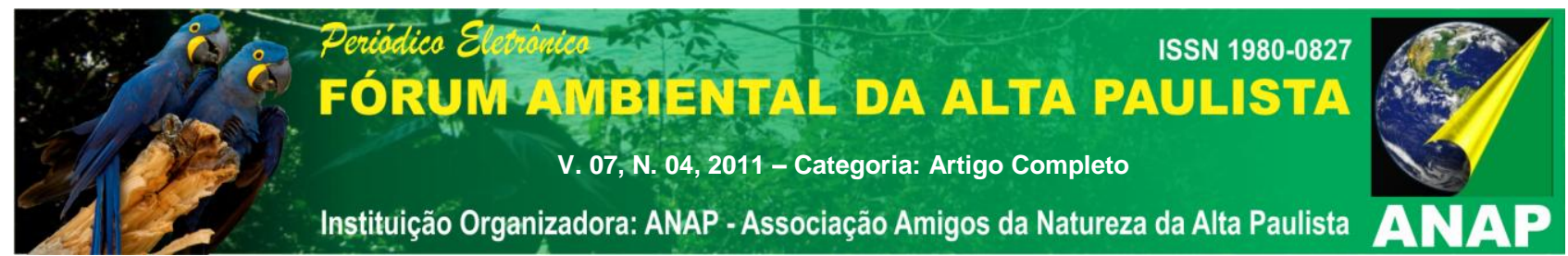

\title{
PROGRAMA AGRICULTURA LIMPA
}

\author{
Paulo Vinicius da Silva \\ Cristiano Mendes \\ Aline de Ferreira de Jesus \\ Denis Paquier Binha \\ Nadiella Monteiro \\ Robson Miranda Lemos
}

RESUMO:O pressente trabalho e uma iniciativa vinculada ao projeto agricultura limpa da Supervisão Geral de Abastecimento da Prefeitura de São Paulo e tem como intuito primordial prestar uma assistência técnica ao pequeno produtor da região de parelheiros, instruindo esses a trabalhar sobre o paradigma da agroecologia e das boas práticas agronômicas. Nesse sentido a assistência técnica efetuada pela equipe de Engenheiros Agrônomos do DEPAB, tem como objetivo levar informações inerentes a sistema de produção agroecologica, ensinando os produtores a trabalharem dentro desse paradigma, incluindo nos sistemas de produção local aspectos como práticas de conservação do solo, substituição de insumos químicos por receitas agroecologicas, de menor impacto ao meio ambiente, organização dos sistemas de produção, escolha adequada das espécies a serem cultivadas de acordo com a época do ano, manejo adequado dos recursos hídricos e preservação ambiental. Para executar tais atividades vem se utilizado diversas ferramentas para instruir esses produtores de maneira correta, como palestras, dias de campo e assistência técnica de forma efetiva, além do auxilio no escoamento da produção. Dentre os principais resultados até o momento podemos citar: Inserção de produtores em feiras livres, fundação da cooperativa e a instituição do protocolo de boas práticas agroambientais. Sendo assim a adoção de políticas públicas com essa ênfase agroecológica, são relevantes do ponto de vista ambiental e social, uma vez que minimizam os impactos ambientais inerentes a pratica agrícola além de melhorar a qualidade de vida e renda agregada dos trabalhadores rurais da região.

Palavras-chave: Agroecologia. Extensão Rural. Assistência Técnica. 


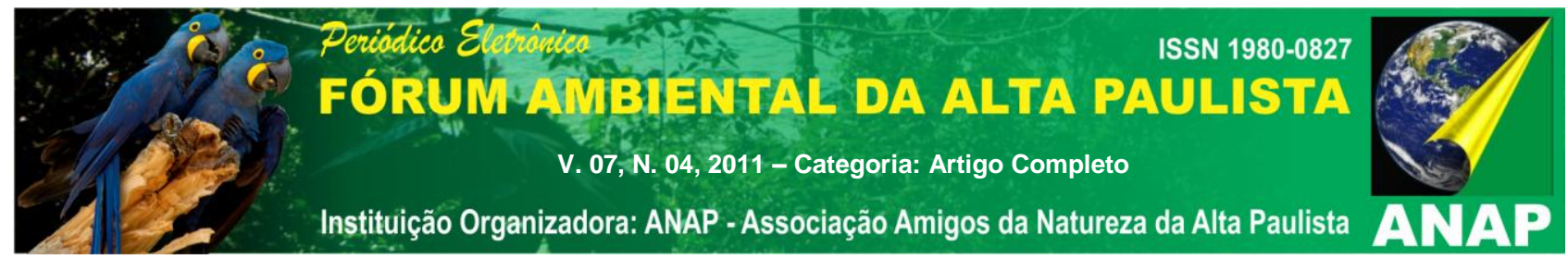

\section{INTRODUÇÃO}

A região de Parelheiros e um distrito rural localizado no extremo sul de São Paulo. É a segundo maior região em extensão territorial, embora seja muito pouco povoada. Tem a maior parte da área coberta por reservas ambientais de Mata Atlântica - nele se localiza a APA Capivari-Monos e a APA Borore-Colonia. Em Parelheiros também estão duas aldeias indígenas de um subgrupo guarani com cerca de mil habitantes. Os poucos habitantes, além dos índios, têm o poder aquisitivo mais baixo da cidade. O distrito dista-se de 15 a 25 quilômetros de Itanhaém e São Vicente no litoral, e uma distância de 50 a 60 quilômetros do centro de São Paulo.

São $353 \mathrm{~km}^{2}$, representando $24 \%$ do município, com ocupação urbana de $2.5 \%$ e dispersa $7.7 \%$. Com a totalidade de seu território em área de proteção aos mananciais, a região compreende remanescentes importantes de Mata Atlântica e as áreas mais preservadas do Município. Inclui parte das bacias hidrográficas das Represas Guarapiranga e Billings, que são responsáveis pelo abastecimento de $30 \%$ da população da Região Metropolitana de São Paulo. É cortado por ferrovia de escoamento da produção agrícola ao porto de Santos e um ramal suburbano desativado.

Apesar das restrições impostas pela legislação ambiental, a região apresenta urbanização intensa e desordenada, com parte da população residindo de forma precária e com sérios impactos sobre os processos naturais de produção de água, devido à impermeabilização do solo, ao desmatamento, ao despejo de esgotos e ao assoreamento dos corpos d'água.

A região tem como características climáticas um elevado índice pluviométrico e mais baixa temperatura no inverno, com geadas freqüentes. Também é área mais preservada do município com remanescente de Mata Atlântica $(62,4 \%)$ e reflorestamento de cerca de 4\% (pinus, eucaliptos). Inclui parte da Bacia Hidrográfica das represas Guarapiranga e Billings.

Parelheiros também representa um cinturão verde de produção agrícola, principalmente familiar, além de representar uma região prioritária para a conservação ambiental e da biodiversidade a qual abrange unidades de manancial de extrema 


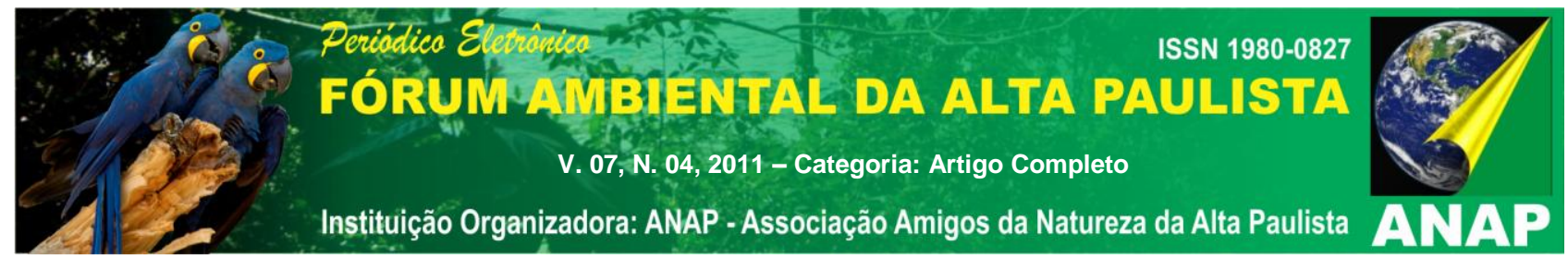

importância para o estado de São Paulo, que garantem o abastecimento de água para quatro milhões de pessoas da região metropolitana de São Paulo, no entanto essa produção de água sofre impactos negativos da expansão urbana desordenada e práticas agrícolas inadequadas.

Diante desse contexto se faz necessário atividades relacionadas à extensão rural, que têm como papel principal intuito o diálogo entre o setor público e o mundo rural, contribuindo ativamente no que diz respeito aos processos de desenvolvimento local (CALLOU, 2008). As dificuldades ainda vivenciadas pelo agricultor familiar no rural brasileiro reafirmam a importância da extensão, estimulando a atualidade do debate em torno das políticas de ATER tanto nas universidades, como em órgãos públicos e privados e ONGs. Nessa perspectiva, faz parte dos princípios da extensão rural uma série de atividades informais, por diversos setores da sociedade voltados às transformações do sistema produtivo-econômico e social do meio rural.

Nesse sentido a prefeitura da cidade de São Paulo através do departamento de agricultura e abastecimento criou o projeto agricultura limpa, o qual consiste numa intervenção na atividade agrícola com técnicas agroecológicas, gerando dessa maneira uma alternativa sustentável para o agricultor, aumentando a sua competividade e agregando valor aos seus produtos permitindo dessa maneira o acesso a novos mercados.

O programa agricultura limpa ganhou um estimulo com o Protocolo de Boas Práticas Agroambientais, o qual criou um mecanismo efetivo para a adoção de práticas agrícolas sustentáveis no município de São Paulo. Além da diminuição dos impactos negativos da agricultura convencional, a adesão dos agricultores ao Protocolo contribuirá para a produção de água limpa para a Cidade de São Paulo, cerca de 20 agricultores da região aderiram ao Protocolo no mesmo dia do evento. Quem adere tem um prazo de 90 dias para entregar um plano de conversão para o sistema agroecológico de produção. $O$ Plano de conversão deve conter, entre outros, os prazos para implementar as metas propostas, que englobam as boas práticas como: ações de conservação de solo e controle de erosão, diversificação da produção, redução até a eliminação do uso de agrotóxicos de e fertilizantes químicos de alta solubilidade.

Nesse contexto mais do que assistência técnica a ação da agricultura limpa na região de parelheiros visa surgir como um conjunto de métodos e técnicas para a 


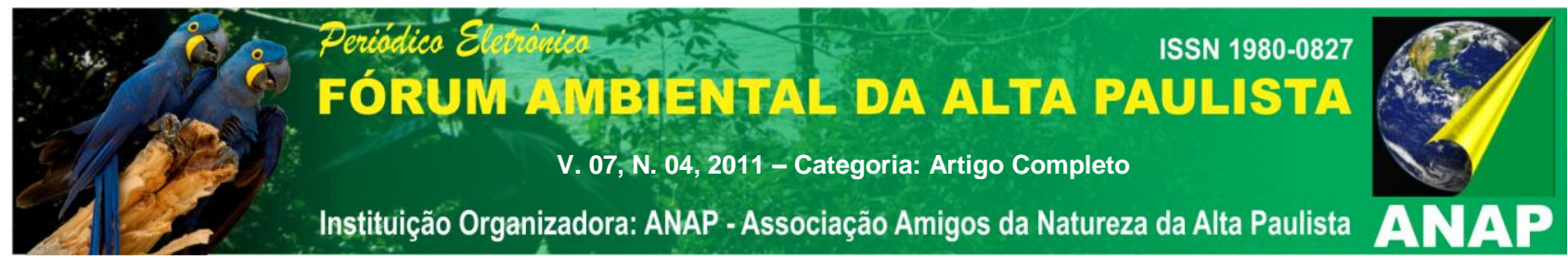

construção coletiva do conhecimento de maneira solidária, permanente, pública e gratuita, visando à melhoria da qualidade de vida das famílias de pequenos produtores rurais, tendo como principal pressuposto a transformação da agricultura convencional com grandes impactos ao meio ambiente e com limitações expressivas na comercialização para uma unidade de produção familiar estruturada baseada no paradigma da Agroecologia, de forma a garantir a melhoria da qualidade de vida das famílias da região, além de gerar uma renda efetiva aos agricultores permitindo dessa maneira que esses permaneçam na terra minimizando os impactos ao meio ambiente oriundos da ocupação desordenada e da utilização inadequada de insumos químicos na região (MDA/SAF, Pnater, 2003).

Logo e de suma relevância inserção da noção de Agroecologia no âmbito das Políticas Públicas para o Meio Rural nesse sentido o trabalho realizado pela Casa da Agricultura Ecológica de Parelheiros tem como objetivo primordial oferecer instrumentos aptos a contribuir com modelos de desenvolvimento rural e de agricultura sustentáveis que respeitem a pluralidade e a diversidade social, econômica, cultural e ambiental, sendo considerada uma reflexão crítica sobre o modelo da Revolução Verde

Logo e de suma relevância inserção da noção de Agroecologia no âmbito das Políticas Públicas para o Meio Rural nesse sentido o trabalho realizado pela Casa da Agricultura Ecológica de Parelheiros tem como objetivo primordial oferecer instrumentos aptos a contribuir com modelos de desenvolvimento rural e de agricultura sustentáveis que respeitem a pluralidade e a diversidade social, econômica, cultural e ambiental, sendo considerada uma reflexão crítica sobre o modelo da Revolução Verde

\section{OBJETIVO GERAL}

Portanto o principal foco do projeto Agricultura Limpa deve ser o de orientar a construção de sistemas produtivos e estratégias de desenvolvimento sustentável norteados pelos princípios da Agroecologia, considerando a amplitude conceitual deste novo enfoque científico, mais especificamente com a atuação focada na conversão da Agricultura Convencional para um sistema de produção agroecológico, levando em conta que essa transição deve priorizar esforços institucionais em atividades específicas que resultarão em estilos de agriculturas de base ecológica ou na transição agroecológica estimulando a 


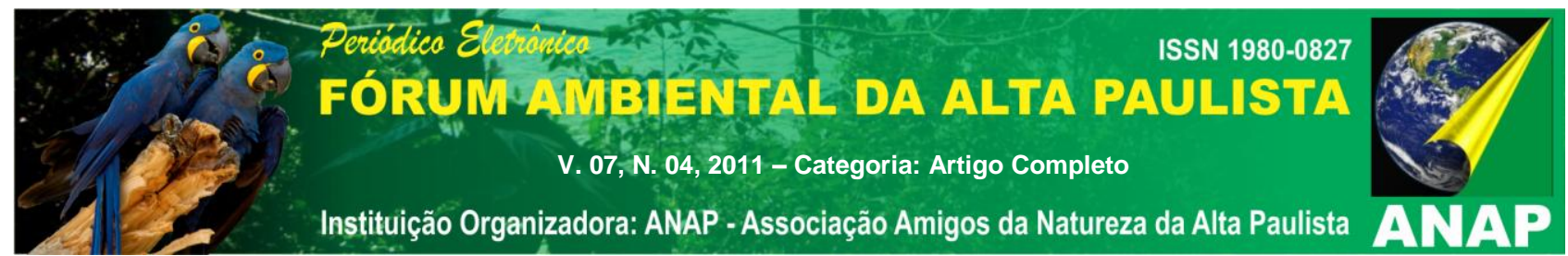

produção de água, de uma maneira geral, articulando com as organizações das cadeias produtivas.

\section{OBJETIVOS ESPECÍFICOS}

Dentre os objetivos específicos o principal foco e utilizar as políticas públicas em detrimento ao fomento da agricultura familiar urbana, dos quais podemos citar como as principais ações:

Oferecimento de assistência técnica aos agricultores através da Casa da Agricultura Ecológica.

Apoio e fortalecimento dos agricultores familiares, incentivando-os a uma conversão gradativa para o sistema agroecologico, estimulando a produção diversificada, promovendo a geração de renda;

$\checkmark \quad$ Capacitação dos produtores, com o oferecimento de cursos, oficinas e dias de campo, considerando suas demandas e os potenciais locais;

Promover a redução gradual do uso de defensivos agrícolas, realizando capacitações e assistência técnica no manuseio, tecnologia de aplicação, redução e substituição de insumos químicos, tendo como meta a eliminação total no uso de tais produtos.

Criação de estratégias de certificação dos produtos, dentro do conceito de certificação participativa, com a viabilização da rastreabilidade da produção, através do conceito de "Região de Origem".

Apoio à comercialização dos produtos, com a criação de espaços específicos para os produtores nos estabelecimentos públicos de abastecimento, garantindo o acesso direto ao consumidor;

Desenvolvimento de ações que facilitem a comercialização direta dos alimentos produzidos ao mercado institucional, utilizando-se do PAA e da Lei de aquisições de alimentos para a Merenda Escolar, como ferramentas iniciais, e a promoção de cooperativas e pequenas sociedades para a exploração mais maciça desse mercado; 


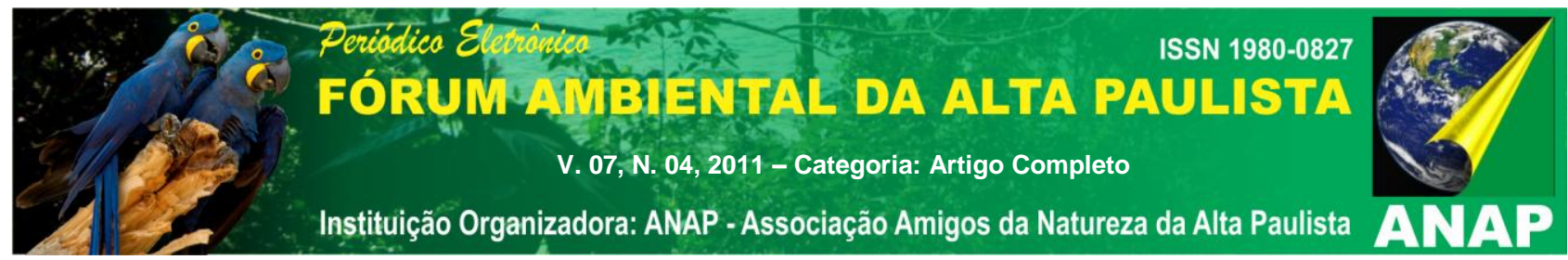

Promoção de melhoria do abastecimento de produtos agrícolas nas localidades envolvidas com o programa, incentivando a venda local com a oferta de alimentos mais baratos, frescos e saudáveis;

Promoção da organização comunitária, através de processos educativos e participativos e a reunião de produtores e outros participantes do programa em associações ou cooperativas;

\section{METODOLOGIA}

Antes de se realizar um projeto de assistência técnica e importante levantar informações inerentes ao sistema de produção da região e a melhor maneira de se levantar esses aspectos e a através de entrevistas com os agricultores em sua próprias propriedades a qual se espera identificar aspectos relacionados ao cultivo, comercialização e mercado consumidor. Tais informações são de suma relevância para se estabelecer um projeto de extensão rural efetivo e que de fato gere benefícios na produção local bem como aumento em sua rentabilidade econômica.

Nesse sentido antes de se iniciar qualquer atendimento ao produtor e realizado um cadastro prévio objetivando levantar informações relacionadas à produção e dificuldades para viabilizar essa, tal procedimento serve para direcionar os atendimentos e aperfeiçoar a ação em campo. Esse procedimento e realizado através de um questionário o qual identifica os principais aspectos relacionados à produção agrícola e traça um perfil do sistema de produção local.

Diante das informações inerentes ao produtor a próxima etapa a ser realizada e a elaboração de um plano individual de ação o qual contempla desde ações básicas relacionadas a aspectos produtivos como tais como: condução da lavoura, utilização de matéria orgânica no solo, calendário agrícola, aumento de diversidade de produção, adubação ,substituição de insumos químicos, controle alternativo de pragas e doenças, manejo de solo, adubação verde, estratégias de comercialização e cooperativismo regional. E valido salientar que esse plano de atuação e realizado de maneira participativa, 


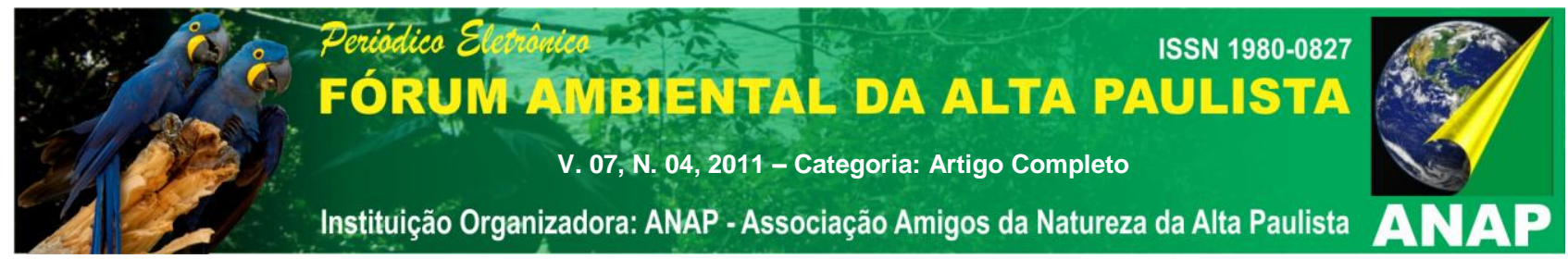

respeitando os conhecimentos do produtor a as práticas adotadas por esse na unidade produtora, além de suas limitações financeiras para tal todo planejamento da produção e respaldado no conceito holístico.

De posse desse planejamento de ação as orientações são prestadas de duas formas, a primeira através de assistência técnica através do fornecimento de informações de forma pontual e individual na própria propriedade rural e segunda na forma de dias de campo o qual representa uma maneira pratica e eficiente de difusão de conhecimentos de forma pratica, participativa e coletiva atingindo uma grande gama de interessados.

Em relação à assistência técnica são realizadas visitas de campo junto ao produtor, as quais visam suprir as dificuldades técnicas inerentes ao sistema produtivo e a execução do planejamento de ação do produtor, essas visitas possuem um intervalo máximo de 15 dias objetivando um constante incentivo e estimulo ao produtor rural, esclarecimento de dúvidas além de possibilitar uma sequência aos atendimentos. Essa orientação e sempre realizada de forma prática e executada junto com o produtor em sua própria propriedade o que possibilita que esse tenha subsídios para realizar as atividades de maneira autônoma sem a dependência da intervenção de políticas públicas ou a presença de um profissional da área.

Todo atendimento realizado ao produtor e acompanhado de um relatório de visitas o qual se descreve todas as atividades realizadas, problemas encontrados e recomendações efetuadas, esse relato e arquivado em um prontuário do produtor, o qual serve como uma referência para posteriores visitas. As visitas também visam efetuar um levantamento dos anseios dos agricultores atendidos, como por exemplo, um projeto de frutíferas diante desse fato se estabelece alterações nos plano inicial e uma analise em relação à viabilidade de execução do projeto bem como os seus custos e parceiros em potencial.

Outra forma de transmissão de conhecimento adotada pela casa da agricultura e através dos dias de campo que tem o objetivo primordial de potencializar o sistema de produção desses, proporcionado atividades que geram resultados positivos na qualidade 


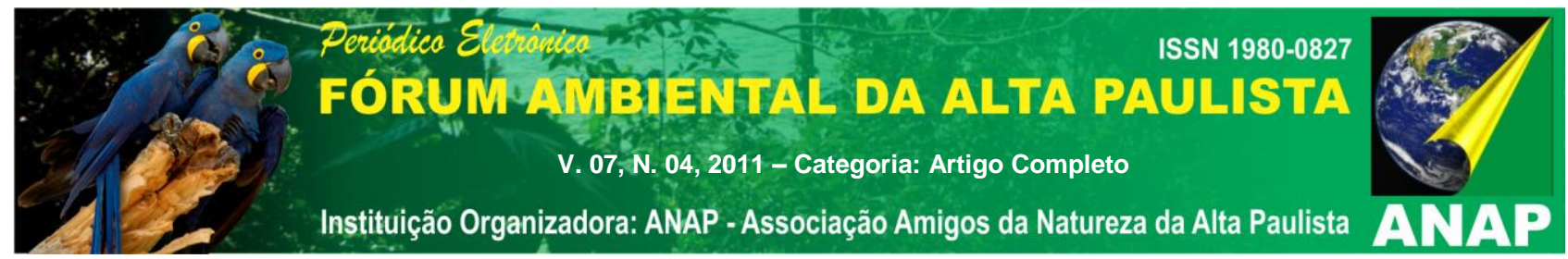

da produção agrícola dentro dos princípios agroecológicos, dessa maneira os tópicos são trabalhados de maneira participativa e convidativa estimulando o produtor familiar, mostrando a esse como se conduzir a sua lavoura além de realizar intervenções práticas na propriedade sempre de maneira conjunta e nunca impondo uma prática a eles, outro aspecto importante e o trabalho dentro do conceito holístico, observando sempre a realidade do produtor e os recursos disponíveis dentro de sua propriedade para execução de qualquer tarefa.

Além da transmissão de conhecimento de forma através do projeto intitulado café na roça, o qual estimula o encontro de produtores permitindo a estes a troca de experiência e das práticas adotadas em suas respectivas propriedades, esse evento também serve para que os engenheiros agrônomos passem novos projetos e informações de interesse aos produtores.

Outra ferramenta utilizada visando o fomento da agricultura familiar urbana e a organização das politicas publicas em detrimento dos produtores rurais, nesse sentido existe a preocupação de se selecionar produtores com DAP na região (documento de aptidão ao PRONAF) também realizamos atividades com a CATI para liberação de novas DAPs, em paralelo se iniciou o desenvolvimento de projetos de custeio bem como a triagem e adequação da documentação pertinente ao acesso as referidas as linhas de credito do PRONAF.

Visando apoiar os agricultores familiares e sensibilizar o público uma das preocupações da casa da agricultura e eliminar a presença do atravessador na comercialização estabelecendo um contato mais direto entre produtor e mercado consumidor, aumentando à rentabilidade inerente a produção agrícola para o produtor e levando um produto com custo final reduzido. Nesse sentido dentro da supervisão geral de abastecimento temos no nosso departamento a administração e coordenação de todas as feiras, mercados e sacolões da cidade de São Paulo, portanto buscamos identificar produtores com potencial para comercialização e orientamos o trabalho desses nas etapas inerentes a produção, além de aspectos relacionados à diversidade de produção e outros nichos de mercado. 


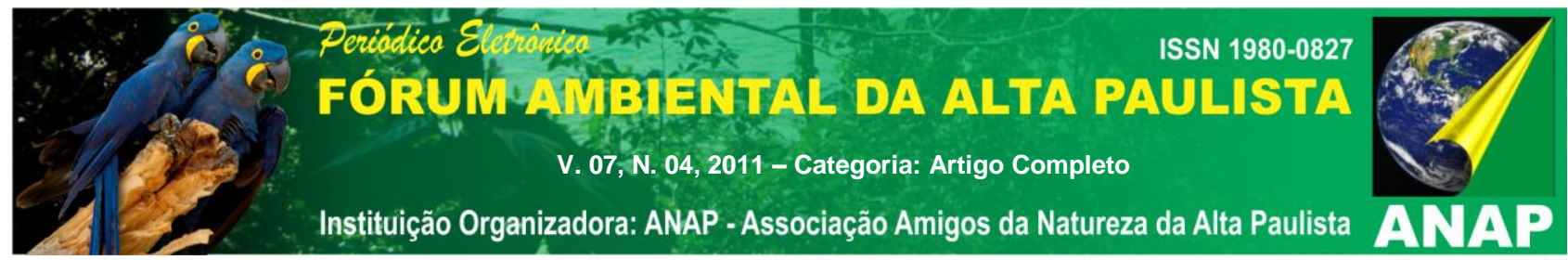

Nesse contexto essas atividades estão relacionadas de maneira direta, visando como intuito primordial uma transição gradativa dos produtores de uma agricultura convencional para um sistema agroecológico de menor impacto ao meio ambiente e região de parelheiros, além de remeter ao agricultor um considerável incremento de renda através do acesso a novos mercados e produção de um produto com maior valor agregado contribuído dessa maneira para organização de um sistema de produção socialmente mais justo.

\section{RESULTADO (S)}

No que diz respeito à realização de cadastro de produtores, atualmente a casa da agricultura conta com 411 produtores cadastro dos quais podemos identificar dois grandes grupos de produção, o primeiro que diz respeito a $56 \%$ dos agricultores cultivando plantas ornamentais sendo as mais recorrentes: Tuias, Buxinho, Moréia, Azaléia, Fênix, Ráfia e grama amendoim e são Carlos, o segundo grupo esta relacionado ao cultivo de hortaliças com uma grande diversidade os demais $4 \%$ estão distribuídos em outros cultivos sendo o mais preponderante o de frutíferas. Isso só na região de parelheiros.

Deste somatório 43 agricultores já aderiram ao Protocolo de Boas Práticas Agroambientais; mostrando um expressivo crescimento pelo interesse na conversão de uma agricultura convencional para uma agricultura agroecológica com menor impacto ao meio ambiente e a produção de agua da região. Nesse contexto foram analisados 25 Planos de Conversão Agroecológica pela Comissão Executiva, constituída por representantes dos governos municipal e estadual da cidade de São Paulo, destes 10 já foram aprovados dos quais 8 estão aptos a utilizar um selo que de procedência do produtos da Guarapiranga, mostrando aos consumidores que esse produto e cultivado de acordo com as boas praticas agroambientais minimizando o impacto ao meio ambiente.

Atualmente o projeto de extensão rural está consolidado, e o principal objetivo da casa da agricultura ecológica de parelheiros o de realizar a conversão de sistemas convencionais de produção para uma agricultura agroecológica de menor impacto ao meio ambiente e em consonância com a produção de água para a cidade de são Paulo, vem 


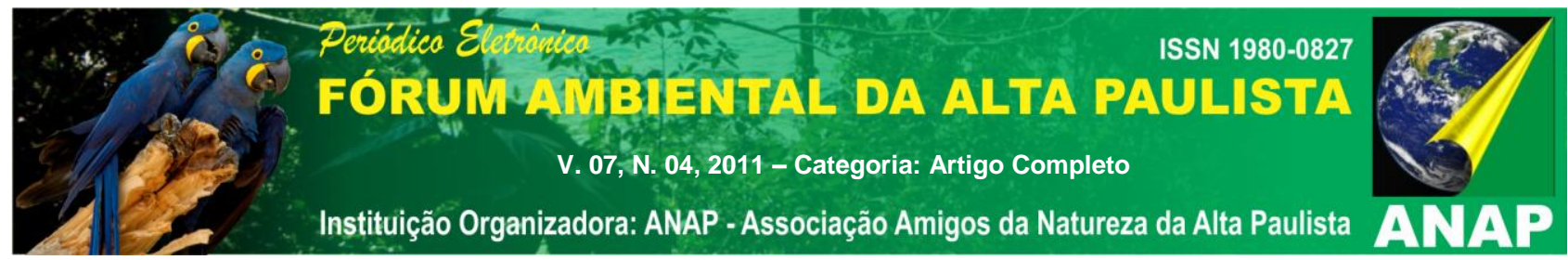

sendo alcançado através de vistas técnicas, as quais ocorrem numa média de 60 visitas mensais, realizadas pelos 05 técnicos em campo.

Nesse período também foram emitidos 10 Documentos de Aptidão ao Pronaf aos produtores da região, dispositivo esse que serve de incentivo e estimulo aos produtores locais uma vez que possibilita a entrada em diversas politicas publicas, como a do PRONAF, programa que na região já possibilitou o acesso ao credito de dois produtores através a elaboração de projetos de custeio e investimento pelos técnicos da casa da agricultura ecológica, além de mais outros oito propostas em analise pelo banco do brasil, iniciativa que serve como incentivo financeiro para a expansão e profissionalização da produção local.

Como incentivo as praticas cooperativistas foi formalizada a COOPERAPAS (Cooperativa Agroecológica dos Produtores Rurais e de Água Limpa da Zona Sul de São Paulo), a qual tem o intuito primordial de fortalecer a produção local e auxiliar em aspectos inerentes a produção e comercialização, servindo como mais uma importante ferramenta para uma agricultura sustentável e de encontro com as boas praticas agroambientais, essa cooperativa conta com um 33 produtores rurais e já se encontra ativa.

Nesse sentido foram realizadas diversas praticas de incentivo a comercialização das quais podemos destacar: Inserção de 5 produtores em feiras, e criação da primeira feira agroecológica em parques localizada a qual inicialmente conta com 10 produtores distribuídos entre os cultivos de hortaliças e plantas ornamentais. Além da comercialização em restaurantes, pousadas, escolas e outras instituições que estão comprando diretamente a produção local da Zona Sul, incrementando a renda dos agricultores e ajudando a divulgar o Programa Agricultura Limpa, temos 40 produtores envolvidos nessas atividades.

Todos esses resultados só foram alcançados em virtude de uma criação de uma rede de agroecologia na região visando minimizar os impactos ambientais oriundos da atividade agrícola convencional, a qual consta diversos parcerisos, como o instituto kairós, fundação mokiti okada, Instituto Biodinâmico, APTA, IAC e secretaria do meio ambiente, contribuindo para o desenvolvimento do Programa e garantindo o apoio da população paulistana para a Agricultura Limpa. 


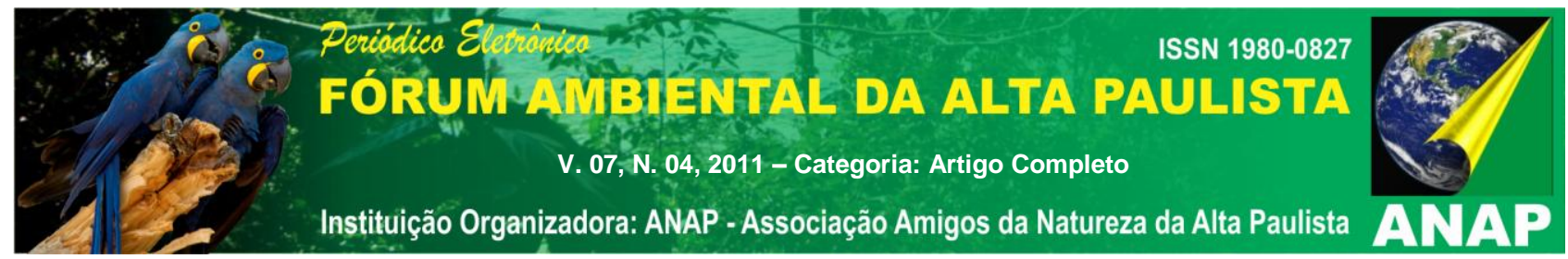

\section{CONSIDERAÇÕES FINAIS}

Diante dos resultados apresentados se torna notório que os órgãos públicos podem exercer de maneira significava atividades inerentes à extensão rural e políticas públicas de fomento a produção familiar fundamentadas no paradigma da agroecologia, fato que pode contribuir para o desenvolvimento agrícola sustentável o que vai de encontro com a preservação ambiental e produção de agua na região de parelheiros.

\section{REFERÊNCIAS}

ALTIERI, Miguel. Agroecologia, a dinâmica produtiva da agricultura sustentável. Universidade Federal do Rio Grande do Sul, 2001 (Síntese Universitária, 54).

ARRUDA. J.; SOUZA, R. S.; Horta Escolar: Importância no Desenvolvimento Integral do Ser Humano. RIO DE JANEIRO, vol1, numero1,; 2020-2028.2006.

ASSIS, R. L. de; AREZZO, D. C. de; ALMEIDA, D. L. de; DE-POLLI, H. Aspectos técnicos da agricultura orgânica fluminense. Revista Universidade Rural - Série Ciências da Vida, Seropédica, v. 20, n. 1/2, p. 1-16, 1998.

BRASIL. Ministério do Desenvolvimento Agrário. Política Nacional de Assistência Técnica e Extensão Rural. Brasília, DF: SAF; Dater, 2004.

BRASIL. Ministério da Agricultura e do Abastecimento. Instrução normativa n 007, de 17 de maio de 1999. Diário Oficial [da] República Federativa do Brasil, Brasília, DF, 19 de maio de 1999. Seção 1, p. 11-14.

BRASIL. Ministério da Agricultura e do Abastecimento. PRONAF — Programa Nacional de Fortalecimento da Agricultura Familiar.-Brasília: set. 1996, 37 p.

CALLOU, Angelo Brás Fernandes; PIRES, Maria Luiza; LEITÃO, Maㅡ do R. F. Andrade; TAUK SANTOS, Maria Salett. O estado da arte do ensino de extensão rural no Brasil: relatório de pesquisa. Recife : Artimpresso, 2008. $141 \mathrm{p}$.

CAMPANHOLA, C.; GRAZIANO DA SILVA, J. Diretrizes de políticas públicas para o novo rural brasileiro: incorporando a noção de desenvolvimento local. In: CONGRESSO. 


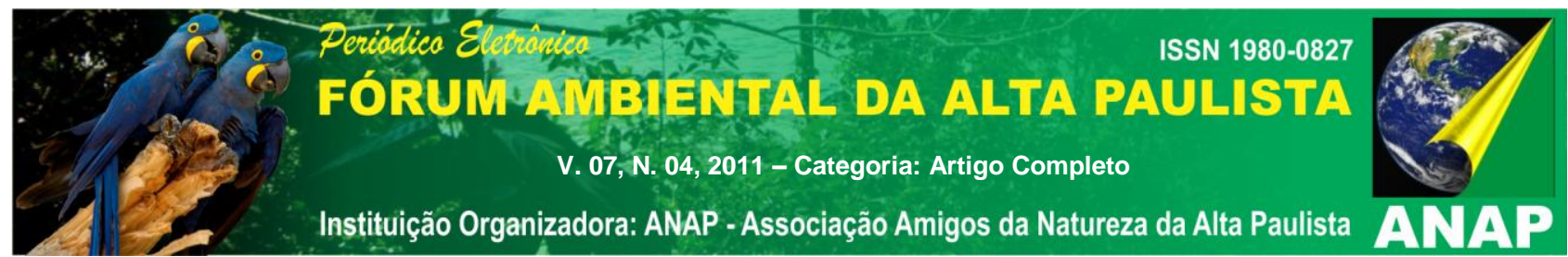

CAMPANHOLA, C.; VALARINI, P. J. A agricultura orgânica e seu potencial para o pequeno agricultor. Cadernos de Ciência e Tecnologia, Brasília, v. 18, n. 3, p. 69-101, 2001.

COSTA, E.Q. et al. Programa de alimentação escolar: espaço de aprendizagem e produção de conhecimento. Revista de Nutrição, Campinas, 14(3): 225-229, set/dez, 2001.

BRASILEIRO DE ECONOMIA E SOCIOLOGIA RURAL, 37., 1999, Foz do Iguaçu. Anais... Foz do Iguaçu: SOBER, 1999. p.47-57

CAPORAL, F. R.; COSTABEBER, J. A. Agroecologia e desenvolvimento rural sustent.vel: perspectivas para uma nova Extensão Rural. Agroecologia e Desenvolvimento Rural sustent-vel, RS, v.1, n. 1, p. 16-37, jan./mar. 2000.

CHRISTOFFOLI, P. (2000). O desenvolvimento de cooperativas de produção coletiva de trabalhadores rurais no capitalismo: Limites e possibilidades. Dissertação de Mestrado , Programa de Pós-Graduação em Administração, Universidade Federal do Paraná, Curitiba, PR.

COSTA, Manoel Baltasar B., et alii. Adubação orgânica. São Paulo: Ícone Editora Ltda., 1994.

FONSECA, Maria Fernanda A. C., TEIXEIRA, Vanessa L. Perspectivas sociológicas do mercado nacional de alimentos ecológicos. Trabalho apresentado no X Congresso Mundial de Sociologia Rural. Rio de Janeiro, 30 de julho a 5 de agosto de 2000.

JESUS, E. L. de. Da agricultura alternativa à agroecologia: para além das disputas conceituais. Agricultura Sustentável, Jaguariúna, v. 3 , p. 3-27, 1996.

JUNQUEIRA, A.H.; LUENGO, R.F.A. Mercados diferenciados de hortaliças. Horticultura Brasileira, Brasília, v. 18, n. 2, p. 95-99, 2000.

LAFORGA, Gilmar. Economia solidária, agricultura familiar e comércio justo: alinhando convergências, apresentando desafios. XXIX Encontro Anual da ANPOCS, 2005. 32.

KIEHL, Edmar José, Fertilizantes Orgânicos. São Paulo, Ed. Agronômica Ceres Ltda. 1985. p. 492.

KIEHL, Edmar José, Manual da Compostagem: maturação e qualidade do composto. São Paulo, 3ª ed. 2002. p. 171.

MARTINS, A. F.G. (2004). Potencialidades transformadoras dos movimentos camponeses no Brasil contemporâneo: As comunidades de resistência e superação do MST. Dissertação de Mestrado, Programa e Pós-Graduação em Ciências Sociais,Pontifícia Universidade Católica de São Paulo, SP. 


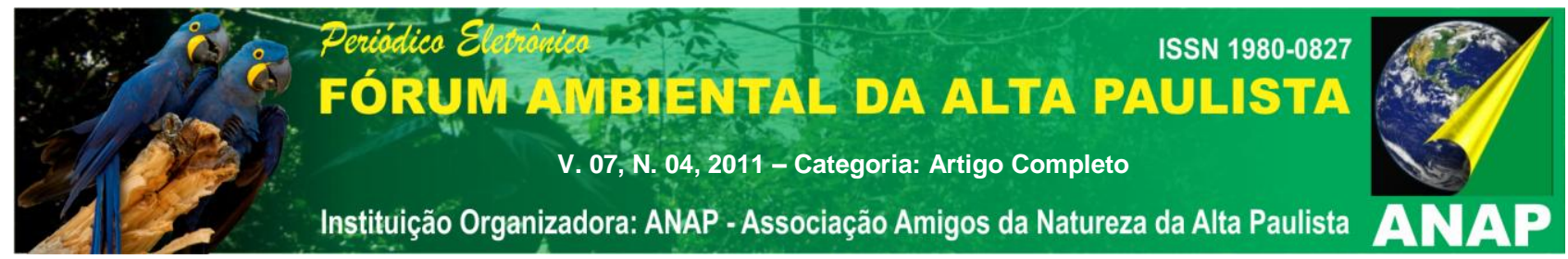

MDA/SDT/CONDRAF Referências para um programa territorial de desenvolvimento rural sustentável". Brasília, CONDRAF/NEAD, Texto para Discussão no 04, 2003.

MINISTÉRIO DA AGRICULTURA PECUÁRIA E ABASTECIMENTO. Mundo: Exportações de produtos agrícolas, exportação total de mercadorias e participação da agricultura nas exportações. Planilha Excell. www.agricultura.gov.br Acesso em 12 maio de 2011.

PEREIRA NETO, João Tinôco, Manual de Compostagem. Belo Horizonte, 1996.

PREFEITURA DA CIDADE DE SÃO PAULO. Supervisão Geral de Abastecimento. Projeto Agricultura Limpa. www.prefeitura.sp.gov.br/abastecimento. Acesso em 20 maio de 2011.

ROSA. M,; A. C. et all. (org). Hortas escolares: O Ambiente da Horta como espaço de aprendizagem no contexto do Ensino Fundamental. Inst. Souza Cruz, 2002.

SISTEMA INTEGRADO DE GESTÃO AMBIENTAL. Rede de Agroecologia da Gurapiranga. Assinatura do Protocolo de Boas Praticas Agroambientais. www.sigam.ambiente.sp.gov.br. Acesso em 20 maio de 2011. 